\title{
TWO-PHASE TURBULENT FLOW IN STRAIGHT HORIZONTAL CHANNELS WITH A SQUARE CROSS-SECTION TAKING INTO ACCOUNT THE INFLUENCE OF VERTICAL FORCES
}

\author{
UDC 532.529:662.613.11:62
}

\author{
Saša Milanović, Miloš Jovanović, Živan Spasić, Boban Nikolić \\ Faculty of Mechanical Engineering, University of Niš, Serbia
}

\begin{abstract}
The paper presents a numerical simulation of a two-phase turbulent flow in pneumatic transport through straight horizontal channels with a square cross-section. The transport of solid particles of ash and flour is taken as the two-phase flow, while air is chosen for the transporting fluid. The motion of solid particles occurs due to the aerodynamic forces of the transporting fluid. The paper considers the motion of solid particles by taking into account the influence of vertical forces, which act on the transported solid particles. In flow modelling, the transported solid particles are reduced to spherical shapes. The stress model of turbulence is corrected by taking into account the influence of the induction of secondary flows of the second kind in the gas phase. The full Reynolds stress model is used to model the turbulence, with the application of the complete model for turbulent stresses and turbulent temperature fluxes. The paper presents the results of the numerical grid with the highest resolution above which the increase of the mesh density does not affect the obtained results. The diagrams of the positions of the transported solid particles are provided for crosssections normal and parallel to the flow direction.
\end{abstract}

Key words: pneumatic transport, solid particles, two-phase flow, secondary flow.

\section{INTRODUCTION}

Two-phase gas-solid particle flows are very often encountered in the engineering practice. The most common examples of this type of flow occur in the systems of pneumatic transport of bulk, granular and powder materials, ventilation and air conditioning systems, process and energy systems. The transporting gas, usually air, acts with its aerodynamic forces on the solid particles of the transported material and moves them along the channel at a velocity smaller than the velocity of the transporting air, yet with the tendency of reaching that air velocity. The motion of solid material particles in

Received November 30, 2017 / Accepted March 8, 2018

Corresponding author: Saša Milanović

Faculty of Mechanical Engineering, University of Niš, Aleksandra Medvedeva 14, 18000 Niš, Serbia

E-mail: msasa@masfak.ni.ac.rs 
pneumatic transport is chaotic and with collisions, both among the particles themselves and between the particles and the channel walls. Generally speaking, two-phase flows are characterized by a specific complex of flow phenomena, which are a consequence of the mutual influence between the gas and the solid phase, chemical reactions between the phases, elaborate gas radiation effects and surface particle radiation effects.

Gas-particle multiphase flow, which may involve a solid or liquid particle, is a significant phenomenon in natural and industrial engineering, such as aerospace, modern chemical industry, energy, metallurgy, material, and environmental protection. Solving gasparticle multiphase flow problems for typical applications are highly important. These applications include burning and flow of metal particles in a solid rocket motor, fluidization in chemical engineering, extraction and utilization of coal, oil, and natural gas for energy, nanoscale manufacturing process, micro chemical engineering, manufacture of electronic devices, and control of biological metabolism. However, the internal rules and mechanisms of gas and particles are difficult to establish because of the diversity and complexity of problems involved. Numerical simulation has become a powerful tool for examining the characteristics of gas-particle multiphase flow because of the remarkable development in computer technology. Three models, namely, Euler-Euler two-fluid model (TFM), EulerLagrange discrete particle model (DPM), and Lagrange-Lagrange pseudo-particle model, are widely used in these numerical simulations.

The Euler-Lagrange DPM has been developed to overcome the limitations of TFM, especially the inability of the latter to trace the path of individual particles. The mechanism of particle-particle collisions can be described by either softsphere or hard-sphere model. The soft-sphere model or discrete element model (DEM), which was first published in the open literature, is the granular dynamics simulation technique proposed by Cundall and Strack [1]. Then, the contact forces could be calculated from the deformation history of the contact using a contact force scheme. A two-dimensional (2D) soft-sphere approach has been subsequently applied to gas-fluidized beds [2], spouted-fluidized beds [3] and the segregation processes of a binary mixture [4], and this model has been extended to three dimensions by considering the particle motion. In the hard-sphere approach, the interactions between particles are assumed to be pair-wise additive and instantaneous. Campbell and Brennen [5] first reported on hard-sphere discrete particle simulation to study granular systems. The coupling of DPM with a computational fluid dynamics approach for gas-solid two-phase flow was first reported by Hoomans et al. [6]. This model has been further used in connection to the kinetic theory of granular flow (KTGF) [7], high-pressure fluidization [8], and circulating fluidized beds [9]. In contrast to the continuum descriptions for the particle phase, DPM can easily describe particle motions, including particle rotations and particle-particle collisions, without limiting the number of particles, sizes, and densities. Therefore, the model can be extended to simulate multiphase heterogeneous chemical reactions, as well as heat and mass transfer. Tanaka et al. [10] introduced DSMC (The direct simulation Monte Carlo) to calculate the particle collisions for a large number of particles in gas-solid flows. Numerical simulations have been performed for a dispersed gas-solid flow in vertical channel [11] and fluidized beds with DSMC method. DSMC has lower computational cost than the hard-sphere and soft-sphere models and is suitable for large-scale simulations. However, details of the particle motion cannot be obtained by the DSMC, and a reasonable sampling number and excellent random number generator are necessary. 
In the paper [12] a modified model for prediction of erosion rate in pipe flows is presented, based on the simulation of fluid fluctuating velocities with Discrete Random Walk model. Turbulence modulation of gas-solid flow in horizontal pipe is investigated numerically using a four-way coupled Eulerian-Lagranigian approach. The particle impingement angle and impact velocity are evaluated and used for predicting the erosion rate by the available and newly developed models. A modified model for erosion was developed that accounts for the effect of particle size to simulate the wall impact velocity caused by fluid turbulence. The pneumatic conveying of spherical particles in horizontal channel with rectangular cross-section is numerically simulated and presented in [13]. Calculations are done for spherical gas beads of different sizes with mass loading of $1.0 \mathrm{~kg}$ particles $/ \mathrm{kg}$ gas and for different wall roughness. Air volume rate has been kept constant in order to maintain a fixed gas average velocity of $20 \mathrm{~m} / \mathrm{s}$. Numerical computations are performed by Euler-Lagrange approach in connection with a Reynolds stress turbulence model accounting for two-way coupling and inter-particle collision. For calculation of particle motion all relevant forces-drag, slip-shear, slip -rotational and gravity, inter-particle collisions and particle rough wall collisions were considered. An Eulerian-Eulerian granular phase model is presented in [14], which is extended with Eulerian-Lagrangian discrete phase approaches for rapid granular flows, with the ability to handle poly-dispersed dilute and dense particle-laden flows. Their modification includes the implementation of a new polydispersed drag law and of new boundary conditions distinguishing between sliding and non-sliding particle-wall collisions. Their hybrid model provides substantial savings in terms of computational effort and cost while maintaining satisfactory simulation quality. In paper [15] vortex structures and particle dispersion in flows around a circular cylinder are investigated by lattice Boltzmann method with non-equilibrium extrapolation method dealing with the computational boundaries. The particles were traced in the Lagrangian framework. The effect of the Reynolds number on the evolution of vortex structures was investigated. It was found that both the Reynolds number and the Stokes number produce significant influences on the particle distribution. The small particles follow the motion of the fluid very well and can disperse into the core regions of the vortex structures. The medium particles concentrate on the boundaries of vortices, and the large particles also assemble in the outer regions of vortices under the influence of the vortex structures.

The paper considers a two-phase air-solid particle flow in horizontal channels with a square cross-section. When turbulent flow is developed in such channels, in addition to the main flow along the channel, other flows are also induced in the cross-sectional plane of the channel. The reasons that lead to the occurrence of secondary flows in the cross-section of the channel are various [16]. The curvature of the channel or different heat loading of the channel walls can initiate the secondary flow known as Prandtl's secondary flow of the first kind, which appears in both the turbulent and the laminar flow. In the developed turbulent flow mode, in completely straight horizontal channels with a non-circular cross-section, the secondary flow known as Prandtl's secondary flow of the second kind is induced. The value of velocity of this type of secondary flow is smaller than the velocity of the main flow and it amounts to $2 \div 3 \%$. However, even such a low level of this type of flow exerts significant influence on the transfer of matter, impulse and heat in the channel and its surroundings. This secondary flow is a consequence of the transverse gradients of the primary shear stresses in the area of the channel vertices and it produces increased shear stresses towards the channel vertices, thus substantially influencing the intensity of heat transfer from the fluid to the channel wall and vice versa [17]. The influence of the secondary flow of the 
second kind cannot be neglected, especially not in the case of a two-phase air-solid particle flow with a high Stokes number, i.e. in the case of the pneumatic transport of smalldiameter solid particles [18].

The paper deals with the transport of solid material particles by applying the full Reynolds stress model of turbulence, which implies the determination of each of the components of Reynolds stress from its own transport differential equation. The solved transport differential equations are not exact conservation equations but modelled ones.

\section{Physical Model of THE GAS AND SOlid PHASE}

To generate and express the secondary flow of the second kind, we will observe a fully developed turbulent flow, which implies that the velocity profiles, i.e. velocities, are constant in the cross-sections of a straight channel with a square cross-section, whose walls are subjected to a uniform temperature flux [19]. It is well known that turbulence lies in the basis of all processes of matter transport, momentum and heat, and that it presents a very unsteady, non-linear, irreversible, stochastic and three-dimensional phenomenon. The occurrence of Prandtl's secondary flow of the second kind in non-circular channels is a consequence of the turbulent flow mode. The generation of the secondary flow of the second kind depends on the level of turbulent fluctuations of the velocity field, where the existence of the gradients of Reynolds stresses promotes the secondary flow of a fluid. In the case of a stationary and incompressible fully developed turbulent flow, the transport equation for the vorticity component $\Omega_{1}$ perpendicular to the cross-sectional plane, when all of the gradients along the axis of the main flow are equal to zero, has the following form, [20]:

$$
\underbrace{U_{2} \frac{\partial \Omega_{1}}{\partial x_{2}}+U_{3} \frac{\partial \Omega_{1}}{\partial x_{3}}}_{\mathrm{A}_{1}}=\underbrace{\frac{\partial^{2}}{\partial x_{2} \partial x_{3}}\left(\overline{u_{3} u_{3}}-\overline{u_{2} u_{2}}\right)}_{\mathrm{A}_{4}}-\underbrace{\left(\frac{\partial^{2}}{\partial x_{3}^{2}}-\frac{\partial^{2}}{\partial x_{2}^{2}}\right) \overline{u_{2} u_{3}}}_{\mathrm{A}_{5}}+\underbrace{v\left(\frac{\partial^{2} \Omega_{2}}{\partial x_{2}^{2}}+\frac{\partial^{2} \Omega_{1}}{\partial x_{3}^{2}}\right)}_{\mathrm{A}_{6}}
$$

The physical meanings of the terms in the vorticity component $\Omega_{1}$ transport equation Eq. (1), which is perpendicular to the cross-sectional plane, are as follows: $v$ is kinematic viscosity, $x_{i}$ are position coordinates in Cartesian coordinate system, $U_{i}$ are averaged velocity components, $u_{i}$ are fluctuating velocity components, $\bar{u}_{i} u_{j}$ are the Reynolds stress components for $i=1,2,3$. $\mathrm{A}_{1}$ represents the convective transport of the vorticity component $\Omega_{1}$ along the main flow of the fluid, $A_{4}$ and $A_{5}$ express the influence of the turbulent stresses on the production or destruction of the vorticity component $\Omega_{1}$, and $\mathrm{A}_{6}$ represents the process of viscous dissipation of the vorticity component $\Omega_{1}$. Analyzing the terms of the previous equation, one can reach a conclusion that the turbulent terms $\mathrm{A}_{4}$ and $\mathrm{A}_{5}$ are of the same order of magnitude, the opposite sign, individually much larger than the convective member $A_{1}$, and play a more dominant role. The viscous member $A_{6}$ is negligibly small, except in the zone of the channel vertices. Thus it can be concluded that the difference between the turbulent terms $A_{4}$ and $A_{5}$ that are of the same order of magnitude as the convective member $A_{1}$, is the mechanism that generates secondary flow. In other words, secondary flow is a consequence of the transverse gradients of the primary shear stresses in the region of the channel vertices [21]. 
Two-phase flows are characterized by a great number of interconnected complex flow phenomena that are a consequence of the influence between the phases. When considering or modelling such flows, a combined approach is adopted for the solution of the flow field. The gas flow is solved by applying the Euler principle - the concept of continuum, while the solid phase is solved by applying the Lagrange approach - the concept of tracing the trajectories of particles. The inter phase interaction between the gas and the solid phase is obtained through an iterative procedure of problem solving, in the following manner:

First step: At the beginning of the integration of the conservation equation, the first solved is the gas phase without the presence of the inter phase term.

Second step: After a certain number of iterations, the obtained field of the gas flow is "frozen" and particles are "let" through it. On the basis of the obtained particle trajectories, the inter phase members of the interaction between the gas and the solid phase are determined.

Third step: The particle trajectories are "frozen" and the flow field of the gas phase is solved again, but this time with the obtained inter phase members from the previous step.

Fourth step: If the solution is not convergent, the second and the third steps are repeated successively until the set criterion of solution convergence is reached.

As far as the definition of a mathematical model of the gas phase is concerned, the following assumptions are adopted: the flow is stationary, three-dimensional, incompressible, isothermal and chemically inert. To define a mathematical model of the solid phase the following assumptions are adopted: particles are of various dimensions, particles do not change their mass while travelling through the channel, particles have a constant temperature through the channel, the influence of particle collisions is neglected, particles lose a certain level of impulse upon hitting the channel walls and internal obstacles, particles move stochastically, i.e. the turbulent flow field of the gas flow modulates the deterministic trajectories of particles that are obtained from the averaged values of the gas flow velocities.

\section{MATHEMATiCAL Model}

\subsection{Mathematical model of the gas phase}

A mathematical model of the gas phase is formed for a three-dimensional fully developed turbulent flow in a straight horizontal channel with a square cross-section [22]. It is assumed that the turbulent flow is stationary and incompressible. The channel walls have a constant temperature that is different from the temperature of the environment. Volumetric gravitational forces are neglected, as well as the effects of the temperature buoyancy. The general equation of conservation of impulse, matter and energy for the gas phase is identical to the well-known equation of field conservation (Reynolds) for a single-phase flow fluid, with the addition of the inter phase source term of the interaction between the gas and the solid phase $S_{\Phi}^{I F}$, which takes into account the influence of solid particles, i.e. the solid phase on the gas phase [21,23]:

$$
\frac{\partial}{\partial t}(\rho \Phi)+U_{j} \frac{\partial}{\partial x_{j}}(\rho \Phi)-\frac{\partial}{\partial x_{j}}\left(\Gamma_{\Phi} \frac{\partial \Phi}{\partial x_{j}}\right)=S_{\Phi}+S_{\Phi}^{I F}
$$


where $\rho$ is fluid density, $t$ is time, $\Phi$ is generalized dependent variable, $\Gamma_{\Phi}$ is generalized diffusion coefficient, $S_{\Phi}$ is generalized source term. According to the adopted assumptions of the physical model, the averaged equations of conservation of matter, impulse and heat have the following forms:

continuity equation: $\frac{\partial U_{j}}{\partial x_{j}}=0$

equation of motion: $\quad U_{j} \frac{\partial U_{i}}{\partial x_{j}}-\frac{\partial}{\partial x_{j}}\left(v \frac{\partial U_{i}}{\partial x_{j}}\right)=-\frac{1}{\rho} \frac{\partial P}{\partial x_{j}}-\frac{\partial \overline{u_{i} u_{j}}}{\partial x_{j}}+S_{U i}^{I F}$

energy equation:

$$
U_{j} \frac{\partial T}{\partial x_{j}}-\frac{\partial}{\partial x_{j}}\left(a \frac{\partial T}{\partial x_{j}}\right)=-\frac{\partial \overline{\boldsymbol{\theta} u_{j}}}{\partial x_{j}}
$$

where $a$ is heat diffusion coefficient, $T$ is averaged temperature, $P$ is averaged fluid pressure, $\theta$ is temperature fluctuation, $\overline{\theta u_{j}}$ is turbulent temperature flux, $S_{U i}^{I F}$ is interphase source term for momentum.

\subsection{Turbulent models}

The starting point for the formation of the stress model of turbulence is the exact transport equation that defines the dynamics of Reynolds stresses [24], and which can be written in the following form for an incompressible fluid:

$$
\begin{aligned}
& \frac{\partial u_{i} u_{j}}{\partial t}+\overbrace{U_{k} \frac{\partial \overline{u_{i} u_{j}}}{\partial x_{k}}}^{b}=\overbrace{\left(\overline{f_{i} u_{j}}+\overline{f_{j} u_{i}}\right)}^{c}-\overbrace{\left(\overline{u_{i} u_{k}} \frac{\partial U_{j}}{\partial x_{k}}+\overline{u_{j} u_{k}} \frac{\partial U_{i}}{\partial x_{k}}\right)}^{d}-\overbrace{2 \boldsymbol{v} \frac{\partial u_{i}}{\partial x_{k}} \frac{\partial u_{j}}{\partial x_{k}}}^{e}+
\end{aligned}
$$

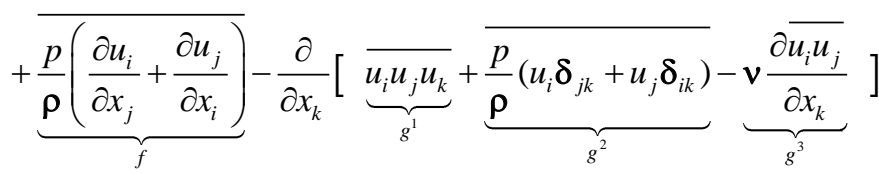

The stress model of turbulence implies a simultaneous solution of the previous transport equation that defines the dynamics of Reynolds stresses with the equation of motion in the averaged form. However, only certain terms of this transport equation can be considered in the exact form $\left(a, b, d, g^{3}\right.$, and $\left.c\right)$, while the remaining terms $\left(e, f, g^{1}\right.$ and $g^{2}$ ) have to be modelled as a function of the available dependent variables. The dependent variables available in the stress model are: the averaged velocity $U_{i}$, the turbulent stress tensor $\rho \overline{u_{i} u_{j}}, \delta_{i j}$ is Kronecker unit operator, $f_{i}$ fluctuating part of body force, $p$ fluctuating part of pressure and $\varepsilon$ the dissipation rate of turbulent kinetic energy. The modelled forms of the term in the previous transport equation lead to the closed form of the transport equation for Reynolds stresses: 


$$
U_{k} \frac{\partial \overline{u_{i} u_{j}}}{\partial x_{k}}=\frac{\partial}{\partial x_{k}}\left(C_{g}^{\prime} \frac{k}{\varepsilon} \overline{u_{k} u_{n}} \frac{\partial \overline{u_{i} u_{j}}}{\partial x_{n}}\right)+\mathrm{P}_{i j}+\Phi_{i j, 1}+\Phi_{i j, 2}+\Phi_{i j, z}-\frac{2}{3} \delta_{i j} \varepsilon
$$

where:

$$
\begin{gathered}
\mathrm{P}_{i j}=-\overline{u_{i} u_{k}} \frac{\partial U_{j}}{\partial x_{k}}-\overline{u_{j} u_{k}} \frac{\partial U_{i}}{\partial x_{k}}, \Phi_{i j, 1}=-C_{1} \frac{\boldsymbol{\varepsilon}}{k}\left(\overline{u_{i} u_{j}}-\frac{2}{3} \boldsymbol{\delta}_{i j} k\right), \\
\Phi_{i j, 2}=-\alpha\left(\mathrm{P}_{i j}-\frac{2}{3} \boldsymbol{\delta}_{i j} \mathrm{P}\right)-\beta k\left(\frac{\partial U_{i}}{\partial x_{j}}+\frac{\partial U_{j}}{\partial x_{i}}\right)-\gamma\left(\mathrm{D}_{i j}-\frac{2}{3} \boldsymbol{\delta}_{i j} \mathrm{P}\right), \\
\mathrm{D}_{i j}=-\overline{u_{i} u_{k}} \frac{\partial U_{k}}{\partial x_{j}}-\overline{u_{j} u_{k}} \frac{\partial U_{k}}{\partial x_{j}}, \Phi_{i j, z}=\Phi_{i j, z 1}+\Phi_{i j, z 2}, \\
\mathrm{P}=-\overline{u_{i} u_{j}} \frac{\partial U_{i}}{\partial x_{j}}, \quad f_{z}=\frac{C_{\mu}^{0.75} k^{1.5}}{0.417 \varepsilon} \frac{1}{x_{n z}}, \\
\Phi_{i j, z 1}=C_{z 1}\left(\overline{u_{k} u_{m}} \delta_{i j} n_{k} n_{m}-\frac{3}{2} \overline{u_{k} u_{i}} n_{k} n_{j}-\frac{3}{2} \overline{u_{k} u_{j}} n_{k} n_{i}\right) f_{z} \frac{k}{\varepsilon}, \\
\Phi_{i j, z 2}=C_{z 2}\left(\Phi_{k m, 2} \delta_{i j} n_{k} n_{m}-\frac{3}{2} \Phi_{k i, 2} n_{k} n_{j}-\frac{3}{2} \Phi_{k j, 2} n_{k} n_{i}\right) f_{z},
\end{gathered}
$$

where $k$ is kinetic turbulence energy, $n_{i}$ are the unit vectors in the Cartesian coordinate system, $\alpha, \beta, \gamma$ are constants determined in turbulent modelling procedure.

The closing of the stress model Eq. (7) is performed by the additional transport differential equation for the dissipation of turbulent kinetic energy:

$$
U_{k} \frac{\partial \boldsymbol{\varepsilon}}{\partial x_{k}}=\frac{\partial}{\partial x_{k}}\left(C_{\varepsilon} \frac{k}{\boldsymbol{\varepsilon}} \overline{u_{k} u_{j}} \frac{\partial \boldsymbol{\varepsilon}}{\partial x_{j}}\right)+\frac{\boldsymbol{\varepsilon}}{k}\left(C_{\varepsilon 1} \mathrm{P}-C_{\varepsilon 2} \boldsymbol{\varepsilon}\right)
$$

The values of coefficients in Eq. (7) and (8) are given in Table 1.

Table 1 Empirical coefficients of turbulent models of Reynolds stresses

\begin{tabular}{ccccccccc}
\hline$C_{g}^{\prime}$ & $C_{1}$ & $C_{2}$ & $C_{\mathrm{z} 1}$ & $C_{\mathrm{z} 2}$ & $C_{\mu}$ & $C_{\varepsilon}$ & $C_{\varepsilon 1}$ & $C_{\varepsilon 2}$ \\
\hline 0.21 & 1.50 & 0.40 & 0.50 & 0.06 & 0.09 & 0.15 & 1.44 & 1.90 \\
\hline
\end{tabular}

The transport differential equation for turbulent temperature fluxes cannot be solved in the exact form as well, so it needs to be modelled. By modelling the terms in the transport equation for turbulent temperature fluxes, the closed form of the transport equation is obtained:

$$
U_{k} \frac{\partial \overline{\boldsymbol{\theta} u_{i}}}{\partial x_{k}}=\frac{\partial}{\partial x_{k}}\left(C_{\theta} \frac{k}{\varepsilon} \overline{u_{k} u_{j}} \frac{\partial \overline{\boldsymbol{\theta} u_{i}}}{\partial x_{j}}\right)+\mathrm{P}_{\theta i}+\Phi_{\theta i}+\Phi_{\theta i, z}+\boldsymbol{\varepsilon}_{\theta i}
$$


where:

$$
\begin{gathered}
\mathrm{P}_{\theta i}=-\overline{u_{k} u_{i}} \frac{\partial T}{\partial x_{k}}-\overline{\theta u_{k}} \frac{\partial U_{i}}{\partial x_{k}} ; \quad \Phi_{\theta i}=-C_{\theta 1} \frac{\varepsilon}{k} \overline{\theta u_{i}}+C_{\theta 2} \overline{\theta u_{k}} \frac{\partial U_{i}}{\partial x_{k}}, \\
\Phi_{\theta i, z}=-C_{\theta 1, z} \frac{\varepsilon}{k} \overline{\theta u_{k}} n_{i} n_{k} f_{z} .
\end{gathered}
$$

The values of coefficients in Eq. (9) above are given in Table 2.

Table 2 Empirical coefficients of models of turbulent temperature fluxes

\begin{tabular}{cccc}
\hline$C_{\theta}$ & $C_{\theta 1}$ & $C_{\theta 2}$ & $C_{\theta \mathrm{z} 1}$ \\
\hline 0.11 & 2.45 & 0.66 & 0.80 \\
\hline
\end{tabular}

\subsection{Mathematical model of the solid phase}

The presence of solid particles in flows that are found in the majority of technical processes greatly complicates the problem, both because of the need to model the flow of the discrete phase and due to the interaction of the phases. The presence of particles creates aerodynamic resistances that condition the change in the momentum of both phases. The mathematical model of the solid phase is based on the Lagrange concept of task solution, which is closer to the physical reality and which ensures a more realistic picture and more reliable prediction of the trajectories of solid particles in fluid turbulence by obtaining more information (trajectories, time of presence in a specific area). On the basis of this concept, the positions - trajectories of solid particles of the transported material are determined [21, 23].

The position of solid particles is determined by solving the equation of motion for every group of particles:

$$
\frac{\mathrm{d} x_{\mathrm{p}}}{\mathrm{d} t}=\tilde{U}_{\mathrm{p}}
$$

The current velocity of solid particles $\tilde{U}_{\mathrm{p}}$ is determined from the momentum equation of the solid phase:

$$
\mathrm{m}_{\mathrm{p}} \frac{\mathrm{d} U_{\mathrm{p}}}{\mathrm{d} t}=\underbrace{\Re_{\mathrm{p}}\left(\tilde{U}-\tilde{U}_{\mathrm{p}}\right)}_{\mathrm{A}}+\underbrace{\mathrm{m}_{\mathrm{p}} \mathrm{bg}}_{\mathrm{B}}-\underbrace{\mathrm{V}_{\mathrm{p}} \nabla \mathrm{P}}_{\mathrm{C}}
$$

where $\mathfrak{R}_{\mathrm{p}}$ is the force of resistance reaction, $\mathrm{b}$ is buoyancy force coefficient, $\mathrm{g}$ is gravity acceleration, $\mathrm{m}_{\mathrm{p}}$ is particle mass, $\mathrm{V}_{\mathrm{p}}$ is particle volume, $\nabla \mathrm{P}$ is continuous phase pressure gradient, $\tilde{U}$ is averaged gas phase velocity.

In the above Eq. (11), the first term on the right side of the equals sign A represents the force of resistance to the relative motion of particles in relation to the gas phase, and it represents the dominant force that causes the motion of solid particles in the direction of the channel axis. The second term B represents the force of gravity, and the third term $\mathrm{C}$ represents the force of buoyancy. The forces of gravity and buoyancy are perpendicular to the direction of motion of solid particles, i.e. to the direction of the force of resistance to the relative motion, but are of opposite sense of direction. Apart from these forces, solid particles are also subjected to the force due to the increase in the pressure gradient, 
Basset, Saffman and Magnus forces, whose influences can be neglected. When transported fluid is liquid (water) the bouyancy force is approximately equal to gravitational force, since the density of particles and water differ slightly. In case that the transporting fluid is air, this density difference is much higher (more than 850 times) and the bouyancy force in this case can be neglected. Due to stronger influence of gravity forces than the bouyancy forces the transported solid particles could be accumulated at the bottom of channel if the transporting air velocity is not sufficient to overcome the resistance forces and keep solid particles flying.

In the previous equation, in the expression for the force of resistance reaction, $\mathfrak{R}_{\mathrm{p}}$ represents the function of the resistance of a solid particle and it can be determined from the expression:

$$
\mathfrak{R}_{\mathrm{p}}=0,5 \rho \mathrm{A}_{\mathrm{p}} \mathrm{C}_{\mathrm{D}}\left|\tilde{U}-\tilde{U}_{\mathrm{p}}\right|
$$

where $C_{D}$ is the coefficient of resistance for spherical particles, $A_{p}$ is particle crosssection, with the Reynolds number $\operatorname{Re}<10^{5}$, and it can be determined from the expression:

$$
\mathrm{C}_{\mathrm{D}}=\frac{24}{\operatorname{Re}}\left(1+0,15 \operatorname{Re}^{0,687}\right)+\frac{0,42}{1+4,25 \times 10^{4} \mathrm{Re}^{-1,16}}
$$

The fundamental problem in the analysis of a two-phase gas-solid particle turbulent flow is the treatment of the mutual influence between the phases. This conclusion is based on the observed change in the momentum, energy and mass of particles while passing through a specific segment of the flow field. When modelling a two-phase turbulent flow, the presence of the dispersed phase causes the appearance of additional sources of the momentum, energy and mass in the gas phase equations. It can be said that when a particle passes through an entire numerical cell, it experiences an interphase interaction between impulse, energy or mass. For example, if a particle moves at a velocity higher than that of the environment, the particle will slow down due to the interaction of the phases, i.e. the velocity of the particle will drop while the velocity of the gas phase in the surroundings will increase. These interphase interaction terms have to be added to the equation of motion of the gas phase, and they describe a change in the momentum of the gas phase due to the presence of solid particles in it. The interphase interaction member represents the force of resistance to the motion of a solid particle in the air current, i.e. the force of resistance to the flow of the fluid around the solid particle, which is of the same magnitude and direction but of the opposite sense to the force of resistance reaction that causes the motion of particles, [25]. This means that the mutual influence between the phases is given by the magnitude of these forces, so that the interphase interaction member is determined by the integration of the particle equation of motion, for each numerical cell:

$$
\mathrm{m}_{\mathrm{p}} \frac{\mathrm{d} \tilde{U}_{\mathrm{p}}}{\mathrm{d} t}=S_{U i}^{I F}
$$

Numerical integration of Eq. (14) has been carried out for every numerical cell. Interphase interaction source term are equal to the particles momentum change for every numerical cell and describe the momentum change of gas phase due to solid particles existence in gas flow and are computed according to the following expression 


$$
S_{U i}^{I F}=\frac{\pi}{6} \sum \eta\left[\rho_{\mathrm{p}}^{0} \tilde{U}_{\mathrm{p}, i}^{0}\left(\mathrm{D}_{\mathrm{p}}^{0}\right)^{3}-\rho_{\mathrm{p}}^{\mathrm{n}} \tilde{U}_{\mathrm{p}, i}^{\mathrm{n}}\left(\mathrm{D}_{\mathrm{p}}^{\mathrm{n}}\right)^{3}\right]
$$

where is $\eta$ is flow rate of particle numbers trough the cell, $\tilde{U}_{\mathrm{p}, i}$ is current particles velocity component, $D_{p}$ is solid particles diameter, $\rho_{p}$ is solid particles density, 0 and $n$ are values at the beginning and the end of the integration time step.

\section{NUMERICAL MODEL}

The numerical model is formed for a fully developed two-phase air-solid particle turbulent flow in a straight channel with a square cross-section, and with the dimensions of the sides of $200 \mathrm{~mm}$. In order to form the mode of the fully developed turbulent flow with constant velocities, and thus induce the secondary flow known as Prandtl's secondary flow of the second kind, an $80 \mathrm{D}_{\mathrm{h}}$ long channel was taken, where $\mathrm{D}_{\mathrm{h}}=0.225 \mathrm{~m}$ represents hydraulic diametar, Fig. 1. For the solution of the posed problem different numerical grids have been used with several different mesh densities. During the numerical simulation the mesh density influence has been tested on the solution convergence. The prescribed time step in numerical temporal integration of solid particles momentum equation is limited not to allow the trajectory of solid particles between two instant of time to be longer than the size of mesh cell. If the time step is large enough that trajectory of solid particles is greater than mesh cell, time step is reduced enough that this criteria is satisfied. In the paper are presented the numerical solutions of the highest resolution mesh density that satisfies convergence criteria $\varepsilon<0,5 \cdot 10^{-4}$. Numerical grid independence has been achieved by the following number of nodes: NX=40, NY=40 and NZ=180, Fig. 2 .

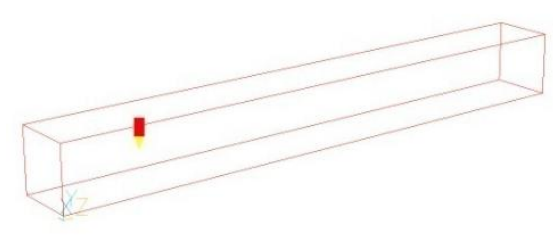

Fig. 1 The shape of the channel

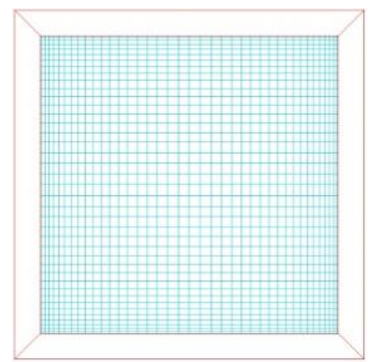

Fig. 2 The numerical grid

The selected numerical grid at the cross-section of the channel is not uniform and the numerical cells are not of the same size. The numerical cells in the central part of the channel are less densely packed and they have larger surfaces, while the cells in the vicinity of the channel walls and vertices are denser and they have smaller surfaces.

The mass flow of solid particles through the cross-section of the channel at its entrance is given as a partial flow in the numerical cells, proportional to the surface of the cells. The numerical cells vary in their surface, i.e. the cells in the vicinity of the channel walls and vertices have smaller surfaces, and the mass flows of particles in them are smaller as well, contrary to the numerical cells located in the middle part of the channel 
that are bigger and have larger mass flows as well. When the entire cross-section of the channel is observed, an even distribution of transported solid particles is obtained along the entire cross-section of the channel. During the simulations, the influence of the fineness of the numerical grid was examined, and the paper presents the results of the highest resolution of the numerical grid above which the fineness of the grid did not affect the obtained results.

To detect the effects of the secondary flow of the second kind in the cross-section of the observed channel, during the transport of solid particles, here considered are two simulation cases of the two-phase gas-solid particle turbulent flow, where the transporting fluid was always air, while the particles of ash and flour were used as the transported material. Upon the formation of the mathematical model, the transported particles were equally distributed at the channel entrance along the entire cross-section of the channel. Firstly, solid particles of ash of $0.14 \mathrm{~mm}$ in diameter and $1800 \mathrm{~kg} / \mathrm{m}^{3}$ in density, and then flour particles of 0.20 $\mathrm{mm}$ in diameter and $1410 \mathrm{~kg} / \mathrm{m}^{3}$ in density, were used as the transported materials. The solid particles of the transported materials were assigned an initial velocity at the entrance of the channel, which corresponded to the suspension velocity of the particles, with the proposed value of the particle suspension velocity of ash of $0.36 \mathrm{~m} / \mathrm{s}$ and flour $1.2 \div 1.5 \mathrm{~m} / \mathrm{s}$. To speed up the iterative process and compare the obtained results, a somewhat greater initial velocity of $2.8 \mathrm{~m} / \mathrm{s}$ was set. Apart from the definition of the initial velocity of the transported material particles, also defined was the velocity of the transporting air at the entrance of $22 \mathrm{~m} / \mathrm{s}$, the pressure of 1 bar and the density of $1.2 \mathrm{~kg} / \mathrm{m}^{3}$.

The solution of the mathematical model was performed in the iterative manner until reaching the solution convergence of $0.1 \%$. The iterative procedure comprised four successively repeated steps. In the first iterative step only airflow field is considered, and the gas phase conservation equations are calculated as if the dispersed phase were absent. The integration conservation equation of gas phase is carried out as if the existence of solid particles does not have influence on gas phase flow field. The presence of dispersed phase causes the appearance of additional terms in gas phase momentum equation as sink term and as source term in solid phase due to interaction between gas and solid phase. In the second iterative step, the computed gas phase flow field is "frozen" with respect to time, and we calculate forces by which gas phase flow field acts on solid particles. In this way in the "frozen" gas phase flow field, the trajectories of solid particles are computed. On the basis of obtained trajectories of solid particles in such a way, the interphase interaction sink term in momentum equation of gas phase and source term in solid phase momentum equation are determined. In the next, third iterative step the gas phase flow field is again calculated but now taking into account the interphase interaction sink term obtained on the basis of calculated trajectories of solid phase which is now temporally "frozen". The second and the third iterative step are repeated until the desired solution convergence criteria of $0,1 \%$ is achieved. The presence of particles in the turbulent flow complicated the problem, both because of the need to model the discrete phase flow and due to the interaction of the phases. Since this was the case of turbulent flow, the transported material particles were affected by both the averaged and the fluctuating components of forces. The dominant parameter that influences the secondary flow of the second kind is the turbulent tangential stresses in the transverse plane of the channel, therefore, it was selected as the parameter for the comparison of the influence of the two-phase flow on the observed phenomenon. 


\section{RESULTS AND DISCUSSION}

The two-phase flow in straight channel of quadratic cross-section has been considered for the validation of turbulence stress model that was used in Po's and Perkins's experiments. The flow conditions are defined by Reynolds, Prandtl number, velocity at the channel inlet cross-section, and constant temperature channel walls. Turbulent kinetic energy and Reynolds stress distribution and evolution have been considered normalized with respect to bulk velocity of channel flow. On the basis of obtained diagrams, the good correlation (agreement) between experimental and numerical results has been achieved. For the need of results comparison between mono-phase and two-phase flow, the numerical simulations of mono-phase gas flow and two phase flow have been carried out for the same boundary conditions of gas phase flow but for several different solid particles dispersed in the gas flow, whereby the mesh density has been kept unaltered. Dominant parameters that influence the secondary flow of second kind are turbulent shear stresses in channel cross section, and they are chosen as parameters for two-phase flows comparison with different solid particles [25].

Two-phase flows are generally characterized by a complex of a large number of interconnected elaborate phenomena, which are a consequence of the multiple components of the mixture. The presence of the disperse phase - solid particles in the fluid introduces new specificities in the consideration of the flow. Systems of fluids with solid particles, in which the fluid is the basic carrier phase, while the particles represent an additive, occur in various technical processes. The disperse phase affects the changes in the characteristics of the transporting fluid and vice versa, the characteristics of the carrier fluid flow affect the behaviour of the particles in this flow. Solid particles of the transported material move due to the action of the aerodynamic forces of the carrier fluid - the transporting air, which become sufficiently large at specific gas velocities so as to be able to carry the material particles in the gas flow. The force that initiates the motion of the transported material solid particles is the force of particle resistance reaction. Apart from this force that acts in the direction of motion of solid particles and causes their motion, particles are also subjected to the particle motion resistance forces, as well as the forces perpendicular to their direction of motion, i.e. the carrier fluid flow. The gravitational and buoyancy force act vertically. In addition to these forces, solid particles of the transported material are also subjected to the force due to the increase in the pressure gradient, Basset, Saffman and Magnus forces. Bouyancy force is significantly smaller than gravity one if the transporting fluid is air, since the density of gases is much smaller than liquids, whereby the solid particles has density quite close to the water density, so the gravity force has dominant influence on solid particles. This disbalance of vertical forces can cause the solid particles accumulation on the channel lower wall.

Since it is the case of turbulent flow, solid particles are subjected to forces that are a consequence of both primary and secondary flow. The forces of the primary, time averaged turbulent flow lift up a solid particle into the main flow, while the forces of the secondary, fluctuation flow disperse the particles in the main flow, i.e. lead them into the apparent state of "flying". The fluctuating components of vertical forces, aided by the action of Magnus and Basset forces, act upon particles by preventing them from accumulating in the channel. If the pulsatile forces are not sufficiently strong to lift up the particles from the bottom in the main flow, i.e. if the vertical forces are not in equilibrium, the motion of the transported material particles is disturbed. In such a case, particles may settle at the bottom of the channel, and maybe even accumulate, which may lead to the discontinuation in the material transport in extreme cases. 


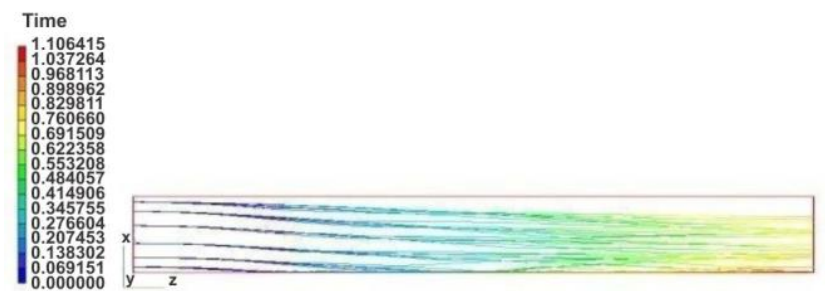

a) Particle trajectories

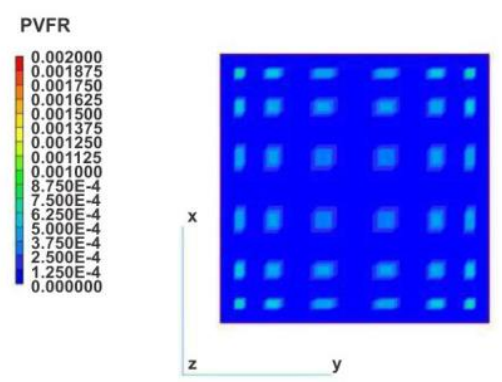

b) Particle concentration at the entrance

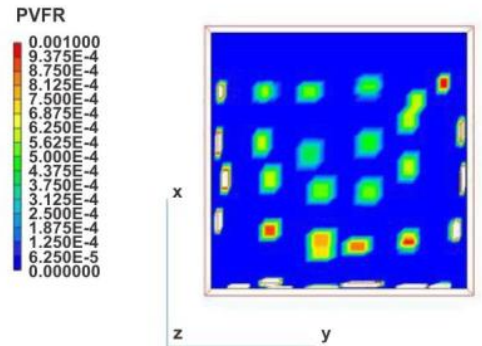

c) Particle concentration at the exit

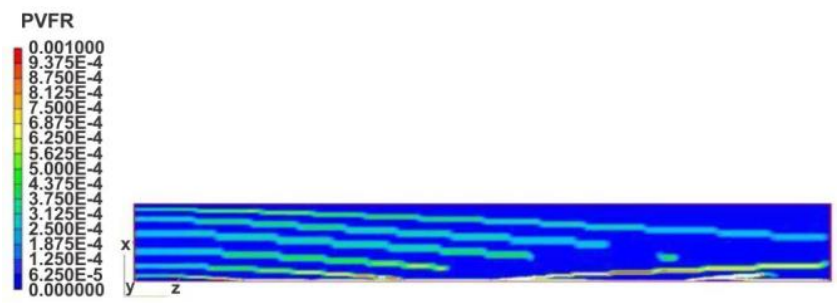

d) Particle concentration along the channel

Fig. 3 Motion of ash particles

When the vertical forces are not in equilibrium, and pulsatile forces are not sufficiently strong to suspend solid particles in the transporting fluid flow, particles accumulate in the lower zone of the channel. Figures 3 and 4 show the trajectories of solid particles along the channel, and the concentrations of particles in the cross-section. Figures 3 c), d) and 4 c), d) show that at the point of exit from the channel particles of the transported material accumulate in the lower part of the channel, i.e. the trajectories of the particles are compacted, Fig. 3 a) and Fig. 4 a). The consequence of this accumulation is the imbalance of the forces that act perpendicularly on the direction of particle motion, where greater imbalances may lead to particle accumulation. Therefore, in extreme cases, if the length of the channel is too great and the velocity of the transporting air too small, the imbalance of the normal forces may even lead to the discontinuation of the material transport. 


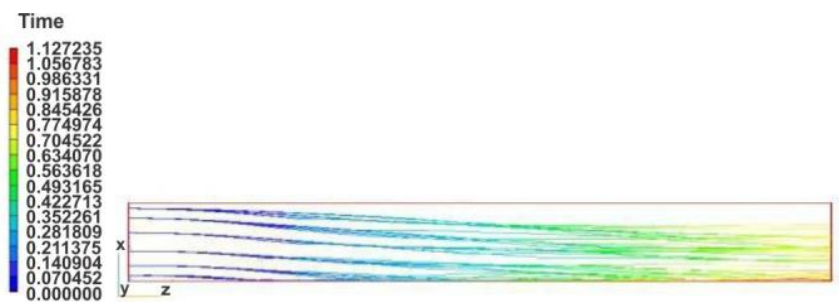

a) Particle trajectories

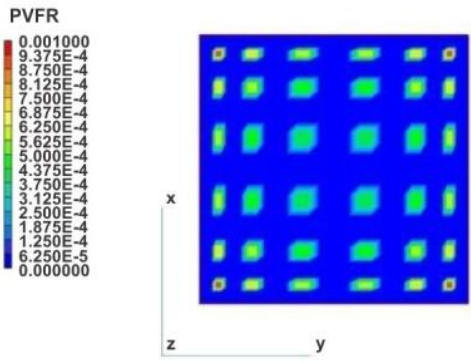

b) Particle concentration at the entrance

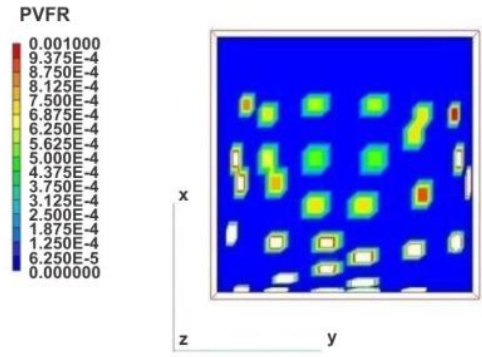

c) Particle concentration at the exit

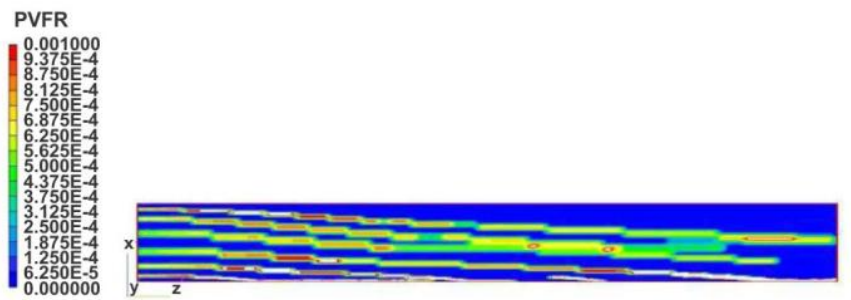

d) Particle concentration along the channel

Fig. 4 Motion of flour particles

\section{CONCLUSION}

The paper considered the fully developed turbulent flow in straight channels with a square cross-section, with the isolated effect of the secondary flow of the second kind. The stress model of turbulence was corrected by taking into account the influence of the induction of secondary flows of the second kind due to the pronounced anisotropicity of the gas phase turbulence as well as the influence of the damped-promoting effects of the interaction between the gas and the solid phase. The full Reynolds stress model of turbulence was used to solve the two-phase flow, with the complete model being applied for turbulent stresses and turbulent temperature fluxes. The numerical simulation of momentum and heat transfer at turbulent two-phase flow has been carried out by using commercial code PHEONICS 3.3.1, which is based on control volume method. All 
numerical computations have been carried out for the same initial and boundary conditions. The conducted numerical simulations yielded the trajectories and the distribution of transported solid particles in the channel, thus it can be concluded that the imbalance of the vertical forces can cause the accumulation of the transported material in the lower part of the channel. If the imbalance of the vertical forces is greater, and the velocity of the transporting fluid is smaller, which makes the aerodynamic forces not sufficiently strong to carry solid particles, it may lead to the accumulation of the particles, and even to the discontinuation of the transport, which has to be taken into account when dimensioning the pneumatic transport channel.

\section{REFERENCES}

1. Cundall, P.A., Strack, O.D.L., 1979, A discrete numerical model for granular assemblies, Geotechnique, 29(1), pp. 47-65.

2. Tsuji, Y., Kawaguchi, T., Tanaka, T., 1993, Discrete particle simulation of two-dimensional fluidized bed, Powder Technology, 77(1), pp. 79-87.

3. Zhao, X.L., Li, S.Q., Liu, G.Q., Yao, Q., Marshall, J.S., 2008, DEM Simulation of the particle dynamics in two-dimensional spouted beds, Powder Technology, 184, pp. 205-213.

4. Feng, Y.Q., Yu, A.B., Yu, S.J., Yu, A.B., Zulli, P., 2004, Discrete particle simulation of gas fluidization of particle mixtures, AIChE Journal, 50(8), pp. 1713-1728.

5. Campbell, C.S., Brennen, C.E., 1985, Computer simulations of granular shear flows, Journal of Fluid Mechanics, 151, pp. 167-188.

6. Hoomans, B.P.B., Kuipers, J.A.M., Briels, W.J., Van Swaaij, W.P.M., 1996, Discrete particle simulation on bubble and slug formation in a two-dimensional gas-fluidised bed: a hard-sphere approach, Chemical Engineering Science, 51(1), pp. 99-118.

7. Goldschmidt, M.J.V., Kuipers, J.A.M., Van Swaaij, W.P.M., 2001, Hydrodynamic modeling of dense gas-fluidised beds using the kinetic theory of granular flow: effect of coefficient of restitution on bed dynamics, Chemical Engineering Science, 56(2), pp. 571-578.

8. Li, J., Kuipers, J.A.M., 2003, Gas-particle interactions in dense gas-fluidized beds, Chemical Engineering Science, 58(3-6), pp. 711-718.

9. He, Y., Van Sint Annaland, M., Deen, N.G., Kuipers, J.A.M., 2006, Gas-solid two-phase turbulent flow in acirculating fluidized bed riser: an experimental and numerical study, Proceedings of the Fifth Word Congress on Technology, Orlando, FL, USA, pp. 1-9.

10. Tanaka, T., Yonemura, S., Kiribayashi, K., Tsuji, Y., 1996, Cluster formation and particle-induced instability in gas-solid flows predicted by the DSMC method, International Journal of JSME, 39, pp. 239-245.

11. Fuzhen, C., Hongfu, Q., Han, Z., Weiran G.A., 2017, Coupled SDPH-FVM method for gas-particle multiphase flow: Methodology, International Journal for Numerical Methods in Engineering, 109(1), pp.73-101.

12. Jaffari, M., Mansouri, Z., Awal, M. Saffar, 2014, Modelling and numerical investigation of erosion rate for turbulent two-phase gas solid flow in horizontal pipes, Powder technology, 267, pp. 362-370.

13. Lain, S., 2013, Study of turbulent two-phase gas-solid flow in horizontal channels, Indian Journal of Chemical Technology, 20(2) pp. 128-136.

14. Schellander, D., Schneiderbauer, S., Pirker, S., 2013, Numerical study of dilute and dense poly-dispersed gas-solid two-phase flows using an Eulerian-Lagrangian hybrid model, Chemical Engineering Science, 95, pp. $107-118$

15. Zhou Hao, Mo Guiyuan, Cen Kefa, 2011, Numerical investigation of dispersed Gas-Solid two-phase flow around a circular cylinder using Latuce-Boltzman method, Computers \& Fluids, 52, pp.130-138.

16. Launder, B.E., Yong, W.M., 1972, Secondary flow in ducts of square cross-section, Journal of Fluid Mechanics, 54, pp. 289-295.

17. Hanjalić, K., Launder, B.E., 1972, Fully-developed asymmetric turbulent flow in a plane channel, Journal of Fluid Mechanics, 51(2), p301.

18. Loicinski, L.G., 1970, Mechanics of fluid and gases, (in Russian), Nauka, Moscow.

19. Bird, B.R., Steward, E.W., Lightfoot, N.E., 2001, Transport Phenomena, New York, Springer, USA.

20. Hinze, J.O., 1959, Turbulence, McGraw-Hil, New York. 
21. Stevanović, Ž., 2008, Numerical aspects of turbulent impulse and heat transfer, (in Serbian), Faculty of Mechanical Engineering, University of Niš, Niš.

22. Patankar, S.V., 1980, Numerical heat transfer and fluid flow, Hemisphere Publishing Corporation, USA.

23. Milanović, S., Jovanović, M., Nikolić, B., Blagojević, V., 2016, The influence of secondary flow in a two-phase gas-solid system in straight channels with a non-circular cross-section, Thermal Science, 20(5), pp. S1419-S1434.

24. Hanjalić, K., 1976, General equations of transport processes, (in Serbian), Faculty of Mechanical Engineering, University of Sarajevo, Sarajevo.

25. Milanović, S., 2014, Research into the turbulent two-phase flow in straight channels with a non-circular cross-section during the pneumatic transport of granular materials, (in Serbian), PhD Thesis, Faculty of Mechanical Engineering, University of Niš, Niš.

\section{DVOFAZNO TURBULENTNO STRUJANJE U PRAVIM HORIZONTALNIM KANALIMA KVADRATNOG POPREČNOG PRESEKA UZIMAJUĆI U OBZIR UTICAJ VERTIKALNIH SILA}

U radu je prikazana numerička simulacija dvofaznog turbulentnog strujanja u pravim horizontalnim kanalima pneumatičkog transporta kvadratnog poprečnog preseka. Kao dvofazno strujanje razmatrano je transportovanje čvrstih čestica pepela i brašna vazduhom koji je izabran za transportni fluid. Kretanje čvrstih čestica nastaje usled delovanja aerodinamičkih sila transportnog fluida. U radu je posmatrano kretanje čvrstih čestica uzimajući u obzir uticaj vertikalnih sila, koje deluju na transportovane čvrste čestica. Pri modeliranju strujanja transportovane čvrste čestice su svedene na sferične oblike. Izvršena je korekcija naponskog modela turbulencije uzimanjem u obzir uticaj indukcije sekundarnih tokova druge vrste u gasnojfazi. Za modeliranje turbulencije korišćen je pun Rejnoldsov naponski model, pri čemu je primenjen kompletan model za turbulentne napone $i$ turbulentne temperaturske flukseve. U radu su prikazani rezultati numeričke mreže najviše rezolucije iznad koje finoća mreže ne utiče na dobijene rezultate. Takođe su dati i grafički prikazi položaja transportovanih čvrstih čestica u poprečnom preseku i duž kanala.

Ključne reči: pneumatički transport, čvrste čestice, dvofazno strujanje, sekundarno strujanje. 